\title{
New Paradigm: Science on Aggression with Sport in the Background
}

\section{Authors' contribution:}

A) conception and design of the study

B) acquisition of data

C) analysis and interpretation of data

D) manuscript preparation

E) obtaining funding

\author{
Jerzy Kosiewicz \\ Josef Pilsudski University of Physical Education in Warsaw, Poland
}

ABSTRACT

In this work, the author focuses in particular on aggressive behavior in competitive sports (highly ranked professional, spectator, and Olympic sports) and on the behavior of fans accompanying sporting events.

Aggression in sports, when considered from the point of view of the regulations in specific disciplines, has two main variants. The first variant is necessary aggression, which is both instrumental and non-instrumental and is potential in the sense that it allows the manifestation of emotions which are not outlined in the rules of the discipline. Thus, aggression is considered necessary when it results from the rules of a given sport.

The second form of aggression is a non-instrumental and unpredictable aggression which is of an emotional origin. It is reactive, characterized by anger, and aims to cause harm. It is not stimulated by the rules of a given sport, but on the contrary is restricted and punished by the rules.

The author also points out that the aggressive behavior of fans before, during, and outside a sporting event will never be necessary in this respect because the rules, guidelines, or specific regulations of a sport apply to the behavior of players, not fans. Therefore, their aggression is potential, emotional, planned, or spontaneous, but never necessary.

KEYWORDS

\section{Reflections on aggression in sports}

\section{The postulate to research violence in sports}

Extensive literature, especially in the English language, has been devoted to the issue of aggression in sports, while there is far less literature on this subject in Polish. While there is a growing interest in and need for an in-depth multi-faceted overview of the researched problem, the existing literature provides a sufficient basis for initiating a plan for establishing a new science of aggression in sports which could serve not only as a social science of sports, but also as a component of research on aggression in general. 
Aggressive behavior and attitudes are primarily researched from the perspective of psychology, sociology, and philosophy. For example, the considerations of Erich Fromm entitled "The Anatomy of Human Destructiveness" are fundamental in the field. These three areas of knowledge could provide a basis for establishing a coherent foundation for the abovementioned science of aggression, and in particular the science of aggression in sports.

This postulate refers to a similar idea first initiated by Maria Ossowska on the basis of research in the field of ethics. It is contained in the work entitled "Foundations of the Science of Morality" (1966), in which Ossowska proposes the creation of a new cognitive discipline called the science of morality. Such a science was to be founded precisely on philosophical, sociological, and psychological assumptions. This new discipline was to be strictly autonomous, in contrast to the sociology or psychology of morality and moral philosophy (understood as a part of philosophy called ethics, moral philosophy could be treated in the narrower sense as an analogue to meta-morality or meta-ethics).

Reflections on aggression in sports can be carried out both autonomously from the point of view of particular sciences, as was indicated at the beginning of the text, as well as in a more integrated, holistic way. It is a well-known fact that scientific disciplines are shaped in various ways. Some associate a groupof issues which have a common subject. Others gather issues which are researched through a common specialized methodology, and still others are linked both by the subject and a specialized methodology. As one might guess, the science of aggression in sports would be a discipline that is connected by including a group of issues and the unity of a subject, and not one common methodology. Its issues would have to be possible to consider, for example, in the light of the relevant specialized methodology of psychology dealing with aggression, sociology, and philosophy which have already tackled this subject.

Ossowska adopted a solution in her science of morality similar to the solutions used in linguistics and other sciences. Linguistics, for example, which investigates language from the point of view of assumptions concerning its meaning, morphology, and phonetics also refers back to certain particular methodologies. Social sciences that focus on sports also tackle diverse issues from the perspective of many methodologies of particular sciences in order to research different aspects of social and interpersonal relations.

The postulated science of aggression in sports would have to deal with a unique and intricate subject of study, which should appeal to different and diverse methodologies of the abovementioned basic sciences.

Ossowska had no followers in the implementation of her great project of ethics, although her research gained widespread recognition. There were no scholars as well-prepared to complete her task as she was. It is hard to find such polymaths nowadays who have such outstanding knowledge in the fields of sociology, psychology, and philosophy. Given this, the prospects for the postulate contained in the title may seem bleak, but not impossible.

In the process of laying the foundation of the science of morality, Ossowska relied primarily on philosophy, including its assumptions, methodology, and substance. She used it to organize issues, aspects, concepts, and theories derived from other scientific disciplines, including the sociology and psychology of morality. This type of procedure is justified on the grounds that all sciences originate more or less directly from ancient philosophy, which was the first and only science until the times of Aristotle. Sociology and psychology diverged from philosophy in the second half of the nineteenth century. Incidentally, "Foundations of the Science of Morality" is a fully theoretical work - the book does not contain empirical studies.

Moral reflection, which was highly developed during pre-philosophical times, as is evidenced by the works of Homer and Hesiod, relatively quickly achieved a high philosophical status in Pythagorean and Sophistic writings (like those of Protagoras), and in the ethical intellectualism of Socrates (Krokiewicz, 2000). A manifestation and far-reaching modification and sublimation of that intellectualism is undoubtedly the sociology and psychology of morality. Their genetic and substantial affinity is obvious. For this reason, the basics of the science of morality as a new scientific discipline, which aspires to become an autonomous science, albeit without much success so far, were founded from a philosophical perspective. 
The assumptions of the study of aggression in sports are similar, although the situation preceding its emergence is different. Both the foundation and the prospect of its development should be philosophical, even though cognitive statements on aggression in sports are dominated by psychological and sociological research. It is precisely philosophy - because of its ordering, synthetic, and fulgurational (Lorenz, 1977) nature - which will undertake, sooner or later, the task of creating deeper scientific reflection on aggression in sports: the explaining and understanding of its sources, meaning, principles, and mechanisms. This is what characterizes the development of individual sciences after they have been established. A deep reflection (or self-consciousness) emerges, which may be divided into two stages. Its first substantive and formal stage is the theory of the discipline and its philosophy, i.e., the philosophy of a given discipline. If one takes biology for example, one may see that it consists of the theory of biology and its philosophy, which constitutes an inherent part of the academic discipline.

This fact is mentioned because during an important and fruitful panel meeting on aggression in sports (including over a hundred debaters), one of the participants, a professor of psychology, questioned the need for research and philosophical reflection to consolidate statements about a given form of aggression.

The considerations of this work are another attempt to gradually expand and, at the same time, order philosophical reflection on aggression in sports, taking into account first of all the achievements of psychology and sociology in this regard.

\section{Aggressive behavior in sports: recognition and divisions}

There are two different points of view regarding aggression in sports: cognitive and ideological. The first involves the study of phenomena in sports as they are - objectively, without falsifying them - in order to describe, explain, and make comparisons. In other words, it presents real situations and the scope and content of discursive reflections related to them as fully as possible and without emotional involvement.

The second position, full of admittedly noble intentions, aims to maximize the appreciation of sports. It takes an ideological approach to sports, that is, it attempts to show sports and their behaviors and values in the best light, trying to hide their faults or anti-values. This, to a large extent, prevents a diagnosis of the current state of affairs, and thus prevents the identification of possible symptoms of social and individual malaise, its causal and symptomatic treatment, and the neutralization or adjustment of its shortcomings.

Aggression in sports, taking into account other criteria of division, may be seen from a cognitive and colloquial perspective. The first is mainly related to psychological, sociological, and philosophical research. This kind of research -especially in English and Polish - points to the existence of two forms of aggression that occur during sports competitions: the kind that results from the rules of a particular sport, which is necessary, and emotional aggression, which focuses on harming the opponent (Kosiewicz, 2010a, pp. 284-295).

Fans of the colloquial point of view believe that aggression only has negative connotations and (contrary to what the aforementioned literature points out), it occurs only in this form. This point of view is reinforced by J. Gąsowski (1993, pp. 13-19), who, referring among other things to A. Bandura (1973), claims that:

"The only criterion for differentiating aggressive from nonaggressive behaviors in sports should be the harmfulness of such behavior and their contradiction to norms. Only then in Gasowski's opinion - will many misunderstandings and talk of positive or innocuous aggression in sports be avoided"(Gąsowski, 1993, p. 14) /own translation/ (It should be noted that the author of this work disagrees with this point of view).

There is a view that sports, by giving vent to urges in physical activity, neutralize the need for aggression in everyday life and promote gentle behavior outside of sports (Biernacka, 1998, p. 16) /own translation/. Perhaps the necessity or possibility of aggressive behavior in sports stimulates and enhances overall aggression, the conviction of one's own superiority, and the need to demonstrate this superiority (Biernacka, 1998, p. 17) /own translation/. E. Aronson (2007, p. 263), relying on the views of psychiatrist W. Menninger, claims that "competition-based games provide an unusually satisfactory outlet 
for the instinctive aggressive drive”. M.A. Holowczak (2003, pp. 387-399) points out, just like F. DeWachter (1987, pp. 17-29), the important educational and moral function of sports in this regard. Holowchak also emphasizes (2003, p. 389) that sports represent a mechanism for cathartic compensation, or that sports are an example of Lorenz's mechanism - that is, they are a hydraulic model which neutralizes aggression (Lorenz, 1966).

L. Berkowitz (1970, pp. 1-7) in turn claims that neither research nor empirical data permit the conclusion that intense physical activity reduces aggressiveness in general (Karolczak-Biernacka, 2000, p. 8).

As is noted by D. Smith, S. Stewart (2003, pp. 384-395), D.S. Kemler (1988), B.J. Bredemeier, D.L. Shields, M.R. Waiss, B.A.B. Cooper (1986, pp. 304-318), and J.M. Brown and N. Davies (1978, pp. 61-70), aggressive behavior increases especially in contact sports, where there is direct body contact with the opponent. In non-contact sports,this type of behavior occurs to a much lesser intensity. The intensity of aggressive behavior is generally considerably higher (compared to girls' and women's competitions), both in contact and non-contact sports, when the competition involves boys and men (Kemler, 1988).

Whether sports are conducive to discharging the motivation for aggressive behavior outside of sports or whether they actually stimulate this motivation, it is undisputable that aggressive behavior is present in sports. This applies not only to competitive, Olympic, or professional sports, but also to mass sports as well as popular, school, and amateur sports, as well as other forms of sports that anyone can participate in.

On the other hand, Jim Parry, who characterizes the violence and aggression in "serious commercial ('marketable') competitive sport" (Parry, 2002, p. 206), states that the problem of violence in sports is paradoxical because, on one hand, as some say, aggression is a quality that is desirable in sports (especially in sports at the highest level); therefore, one cannot be surprised that sports attract and draw aggressive individuals and that sports stimulate ("produce") aggression. On the other hand, violence and aggression in sports is consistently prohibited (Parry, 2002, p. 206). Incidentally, this paradox can be considered in light of the objectives of aggression (and possible violence) which is statutory and necessary as well as non-statutory and forbidden by the rules (this consideration is included in further parts of the text). Both forms of aggression are usually very attractive for the fans of a given player or team applying them, and also, possibly, for the emotionally uninvolved viewers. However, they cause more or less spectacular opposition from rivals and their supporters.

Aggression that appears in sports is primarily related to athletes themselves and their behavior towards their opponents and the social environment associated with sports. This especially applies to football fans.

This paper will focus especially on aggressive behavior in competitive sports (both Olympic and professional) and, to a lesser extent, on the behavior of fans that accompany sporting events.

\section{Statutory and non-statutory aggression}

Aggression in sports, when considering the case from the point of view of specific disciplines, may on one hand be statutory, i.e., necessary, immanent, coherent, instrumental, and task-focused. On the other hand, it may be emotional and focused on harming the opponent; it would thus be non-statutory, or potential in the sense that it allows for the manifestation of emotions unconnected with the principles of the competition.

Statutory aggression, which is necessary, occurs when aggressive behavior results from the regulations of a given discipline. This applies to contact sportsand also to combat sports such as wrestling, boxing, judo, jujitsu, karate, and aikido. Players who avoid combat and do not exhibit aggressive behavior in this regard are admonished and urged to do so, and if they refuse, they are penalized by the judges and ultimately excluded from combat.

The second form of aggression is non-statutory; it has an emotional character and aims to harm the opponent. It is unpredictable in the sense that it is of a reactive, angry, and highly spontaneous character. This form of aggression, especially reactive aggression, is present to a greater extent in direct contact sports than in other kinds of sports (Kemler, 1988; Smith and Stewart, 2003, pp. 384-395). It is not stimulated 
by the rules of the sport; on the contrary, it is restricted and punished by these rules. A boxing fight for the world title between super-heavyweight athletes Mike Tyson and Evander Holyfield in 1996 may be a case in point here. When during the famous fight both boxers bombarded each other with fiercely powerful blows in accordance with the rules, they were demonstrating statutory aggression which was instrumental, taskrelated, immanent, coherent, and necessary, even though they used different techniques and tactics which might not have been necessary. They were of aleatoric character (Kosiewicz, 2010b, pp. 277-283) - they allowed both fixed and random solutions to this issue.

In contrast, when Tyson bit off a piece of Holyfield's ear, he displayed harmful, stigmatized, punishable, and drastically aggressive behavior that went beyond the definition, regulations, or rules of the discipline. Apart from moral restrictions, Tyson had to face sanctions from the Code of Administrative Procedure. He was banned from participation in high-paying boxing fights in most states of the USA, and he was not paid the hefty purse (several million US dollars) for the fight with Holyfield.

The United States, where another form of competitive aggression has established itself (e.g., in hockey), saw the first criminal trial for a non-statutory act of hooliganism on the ice rink (Ingham, 1985, pp. 29-33).

The various terms that are used in relation to the aggressive behavior of players who proceed in accordance with the rules of competition are not specific enough. For example, the expression "task-related aggression", used by B. Karolczak-Biernacka (2000, p. 6) to refer to the views of J. Reykowski (1975), describes a type of aggression that may, but does not have to, result from the rules of the game. It may in fact be associated with non-statutory pre-planned aggression that aims to harm the opponent. It may also concern aggression which is not connected with sports players. For example, it could be intentional aggression based on hooligan behavior with the objectives and aim of verbal and physical aggression towards the players or fans of the opposing team, those responsible for maintaining order, and individuals who happen to be present both on the sports site (e.g., a stadium or an ice rink) and beyond it.

In turn, the concept of instrumental aggression (used, among others, by Smith and Stewart, 2003, pp. 384-395; and by Kemler, 1988) has reductionist properties and points to an instrumental - in this case, one-sided and incomprehensive - treatment provision of a specific discipline, requiring or encouraging players to use violence as a manifestation of the competitive spirit which is necessary for or leads to success. In this case, the aggression may be connected with non-statutory and non-sport aggression, just like taskrelated aggression.

The term "statutory aggression" indicates both the object (the subject) and place of aggressive behavior, its aims, forms, and the instruments (means) necessary for carrying out the goal specified in the rules of the competition associated with the specified sport. This kind of aggression, which relates only to opponents in a competition, stems from overall and comprehensive characteristics of the discipline. For this reason, among others, it is coherent; it is intrinsically blended and inseparably related to the discipline, and therefore it is necessary. Without aggression, a given discipline and competition associated with it could not exist.

Although the term "statutory aggression" seems most appropriate for describing the first form of aggression, when one adds other complementary terms to it, such as necessary, task-related, immanent, coherent, or instrumental, then one receives a comprehensive picture of aggression which results from and does not contradict the rules of the sport.

The aggressive behavior of fans before, during, and outside sporting events will never have the character of necessity in this respect because the rules, assumptions, or specific sport regulations apply to the proceedings of players - not fans. Therefore, their aggression is potential and emotional, whether it is planned or spontaneous. It may also have an instrumental and task-related character, but it will never be necessary, coherent, or immanent, because it is not imposed by the rules of a particular sport. This includes both fans who manifest harmful aggression (e.g., hooligans) as well as those who quietly support or watch a game; although they are or tend to be interested in a particular sport, they are not affected by the rules of the game, perhaps except for those which specify the location of sports fans during the event. 
Statutory aggression (necessary, instrumental, task-related, immanent, and coherent) is, just like in combat sports or team sports, protected, or, colloquially speaking, accompanied by legal, moral, and social values.

A person who causes the death, permanent disability, illness, or trauma of an opponent during a sporting event will not face any sanctions in terms of the administrative or criminal law if the person was following the rules of the game.

For example, a boxer who, following the rules of combat related to statutory aggression (necessary, etc.), kills or permanently or temporarily damages an opponent will not face any restrictions related to his practice of boxing on the basis of any article or paragraph of administrative proceedings. Nor can any norms of criminal law that would institute proceedings against such a person be used.

No moral sanctions or social condemnation would be used against such a person, either.

Legal, ethical, and moral punishment can be applied to the aggressive behavior of athletes and other people involved in but not formally associated with sports (e.g., fans) whose conduct does not constitute statutory aggression (required, etc.).

The second form of aggression mentioned above, which is associated with non-statutory activities with an emotional background, is characterized by the fact that its main objective is to harm an opponent or cause discomfort in the form of negative physiological, mental, and relational stress (that is, affecting changes in social relations within the team) which is not accounted for by the principles of competition. It is unpredictable in the sense that it is a non-statutory, reactive, angry, hostile, and highly spontaneous behavior. It is not stimulated by the rules of the sport; on the contrary, it is restricted and punished by these rules.

Reactive, angry, or hostile behavior also appears in the aggressive actions of the first type; however, the interpretation of such behaviors does not have to be negatively evaluated. For example, reactive behavior is natural in combat sports. Players react aggressively, among other things, to the successful or unsuccessful attack of an opponent, an observed deficit in their training, wrong tactical or technical solutions (e.g., a gap in defense), or the signs of increasing fatigue.

One can also begin a competition with a hostile attitude towards the opponent. Hostility or anger can also be caused by the negative behavior of the opponent. The above are manifestations of emotional activity. They may have the purpose, as in the other types of aggression, of harming the opponent, and therefore weakening them or eliminating them from the contest. In boxing, this is the aim of painful blows to the head, jaw, liver, or solar plexus; they are meant to lead to a knock down and an impressive knock out. In this case, the motivation is of secondary importance. What matters most of all is whether the aggressive behavior complies with the rules. Some observers may, in the moral or professional sense, negatively assess excessive anger and hostility towards an opponent (at most, and only if it does not undermine the principles of the competition).

All manifestations of reactive, angry, hostile, or emotional aggression may be the objectification of highly spontaneousand, at the same time, unpredictable behavior. The above manifestations are appropriate and acceptable when they occur during the aggression of the first type, in contrast to its other form, because they are taken into account or even stimulated by the rules of the game. In this sense, they are a manifestation of statutory aggression. Conversely, if the abovementioned acts extend the rules of competition, they are non-statutory, that is, unacceptable. It should be emphasized once again that the motivation for aggression is therefore of secondary importance. What counts above all is its objectification and compliance or noncompliance with the rules.

According to A. Fąfara and B. Karolczak-Biernacka (2000, p. 6), aggression in sports is continuing to intensify. The above researchers claim that one of the reasons for this phenomenon is the tendency to further increase the attractiveness of sporting events. This happens thanks to the creation of stringent conditions for taking part in the competition and the game itself, including provisions forcing quick, aggressive actions - in other words, a fierce fight. 
This statement is legitimate, although the author does not find a clear indicator of whether it is a positive or negative phenomenon. The author is under the impression - perhaps a mistaken one - that the above psychologists deplore this situation. In this respect, the author has a rather ambivalent view. The fact that there is a growing interest in sports as a form of spectacle has the author's positive evaluation, as does clarifying and improving the rules of games and increasing the attractiveness of a sporting event. This stimulates coaches and players to raise their qualifications, skills, and technical and tactical competence. It motivates them to become more active before and during the competition and to perform the statutory (necessary, etc.) aggressive behaviors which intensify the event and add more emotions to it. This type of aggression is by all means desirable.

The related mental tension and social, club, financial, or political pressure increasingly stimulates and motivates non-statutory aggression, which is reprehensible and unjust to a player's opponents and is a testimony for pursuing victory at all costs. It undermines the humanistic values of sports, of which the highest is the dignity of and respect for the other person. Sports were created for people - for the fulfillment of their dreams, expectations, and needs (Kosiewicz, 2005, pp. 363-370) /own translation/.

Non-statutory aggression is not an innate part of sports, even though it occurs in the sporting arena. It is directed against the provisions of a specific discipline. It is therefore directed against a particular sporting activity, which is defined to a greater or lesser degree by the very principles and rules that specify its essence, identity, nature, characteristics, and the rules of the competition. It also rises against the specific and acceptable forms of movement characteristic for a given sport and associated with its definition. The exception in this respect are tactical fouls, also referred to as "good fouls" (Li-Hong, 2005, pp. 6-7; Simon, 2007, pp. 223-224; Kosiewicz, 2014, pp. 45-46). In this case, the rules of the game are treated instrumentally as a means to achieve the desired purpose in a competition.

Given the above assertions, it can be said that in a sports event, aggression that increases the audience numbers and promotes the development of the sport is positive or statutory aggression. However, the converse behavior, unsportsmanlike and negative aggression which should not occur in sports and is therefore non-statutory (with the exception of the good foul), often appears instead. From this point of view, it does not belong to sports at all (with the exception of the good foul). The development of this first type of aggression is advisable, while the other should be limited as much as possible (with the exception of the good foul). However, its complete elimination will never be possible, in the author's opinion.

The above distinction between positive and negative aggression originates in the inspirational sense from Erich Fromm, who wrote in "The Anatomy of Human Destructiveness" about violence in general from a psychological and philosophical point of view. He claims that "harmless" defensive aggression remains at the service of the survival of individuals and species and ceases when the threat ceases to exist.

"Malignant aggression, i.e., destructiveness and cruelty, is specific to the human species and virtually absent in most mammals" (Fromm, 1973, p. 4).

That distinction transferred to the sphere of sports indicates that harmless aggression is aggression resulting from the necessity to comply with the rules of a given discipline. In contrast, harmful aggression is against a discipline's rules and undermines its identity in order to harm the rival as much as possible (with the exception of the good foul). It manifests itself in the non-statutory way. This is an activity which enhances destructiveness in sports through additional prohibited measures which are not included in the accepted canon of the training, competition, education, and morality of the sport. This type of aggression is surprising; it causes discomfort and aversion to such forms of competition (with the exception of the good foul). In this sense, this aggression and destructiveness is both anti-humanist and dehumanizing. 
The non-statutory (unsportsmanlike, non-sport, anti-humanistic, dehumanizing, harmful, negative, destructive, and emotional) aggressive behavior of players may originate from the following individual and social reasons:

a) an inability to suppress the drive of negative emotional aggression;

b) a lack of knowledge about or an inability to use an appropriate compensation mechanism;

c) a desire to harm the opponent in a non-statutory way, resulting in frustration and helplessness in relation to another person's superior skills or higher-level technical and tactical training and endurance;

d) negative feelings towards the opponent or opponents as a result of the environment before a sporting event. This applies to teammates, coaches, club staff, sponsors and journalists, radio, television, politicians, and others who more or less openly incite negative emotions towards a team's opponents.

The causes and possible signs of aggression can also be divided into the following behaviors:

a) spontaneous: arising from uninformed or undefined individual (immanent) and environmental (transcendental) causes;

b) intentional: resulting from the previously adopted plan (screenplay, score) of the game. Both the assumptions and their objectification are proof of the negation of the existing social norms, including sporting, educational, moral, and administrative ones (except for the good foul).

The first form of behavior, if the player displays it too often, may be neutralized, treated, or eliminated by consistent professional educational and psychological or psychiatric treatment. If such behavior is too irritating, annoying, or harmful it may be eliminated using selection - in other words, eliminating such a player from competition, training, and even from participating in the sport.

Trainers, who can reduce the impact of or completely eliminate such aggression by their beliefs or under the pressure of their principals and a sports-related environment, have the greatest influence on the existence of this aggression.

Both forms of aggressive behavior can be evaluated from the point of view of the administrative and criminal law if they are determined to be too harmful.

\section{Aggressive behavior of fans}

Sports have become a catalyst for the manifestation of aggression in people who are permanently undervalued in society. This is particularly true for frustrated football fans, people who do not necessarily come from the fringes of society, but from its lower classes, and who feel they are unable to find their place in life. In a group, they "feel their own strength", so they attempt to influence the situation in the stadium and beyond it. The fact that they are in the center of public attention because of their rowdiness and hooliganism turns them into heroes in their own eyes and in the eyes of their "buddies". During and after matches, they are shown on television; they give interviews, and clubs negotiate with them. They are convinced that they are an indispensable part of a sporting event and that they co-create it by having true fights in stadiums with their opponents and the opponents of their favorite team. While their sports heroes only engage in symbolic and conventional combat based on rules and regulations, they fight in earnest, using measures which can injure and kill. They live on the margins of other cultural and civilizational events between particular games, waiting for their minute of fame during a public display of impunity and collective aggressive force, devastating halls, stadiums, and their surroundings, and having street fights with the police or participating in pre-planned illegal fights. Sports help them focus and manifest their aggression; it becomes 
a compensatory mechanism, an illusory and substitute form that neutralizes their frustration, undervaluation, and unmet needs in another sphere.

Many countries have succeeded in controlling this social evil by means of comprehensive and consequent control measures associated with the activity of fan clubs, such as the efficient monitoring of sports venues, the introduction of ID cards and the registration of hooligans, and security measures between sectors of fans, the audience, and the field. These measures have also been associated with the personal control of persons suspected of attempting to bring alcohol or dangerous objects into a sports facility. However, according to philosophers, sociologists, educators, and social psychologists involved in sports, these types of preventive measures are not adequate or sufficient. They bear the signs of therapy treating only symptoms and not the causes of this social illness, which is aiming to find a spectacular way to release itself. It is not enough to cure superficial symptoms of the disease attacking undervalued groups of young people of postindustrial and postmodern society with "physiotherapy" (that is, therapy with a stick). This type of treatment could lead to even more dangerous consequences - a cumulative explosion of its discontent at an unknown location and time and in an unknown form (Kosiewicz 2004, pp. 330-331).

\section{Conclusion}

All aggressive behaviors that do not result from and are not connected with the rules of a competition, i.e., a particular sport, may incorporate the hallmarks of accidental or deliberate (scheduled in advance) fouling (Kosiewicz, 2014, pp. 32-33). Behaviors including the above signs are considered reprehensible from the standpoint of the rules of competition (with the exception of the good foul) and are sanctioned with the applicable penalties.

That penalization is of a universal character. It is commonly used regardless of continent, country, nationality, race, the size of a social group, or the place and time of the event taking place. No relativism can be applied in such a case.

Harmful aggressive behavior that occurs during sporting events may also be additionally sanctioned with punishment specified in the Criminal Procedure Code (CPC), the Code of Administrative Procedure (PAC), or the Code of Civil Procedure (CPC) of the country in which the specific competition took place or the state of the designated player, i.e., the state to which the player will return after the competition is over. Penalization may be connected with the use of prohibited forms of doping. However, the possible criminal, administrative, and civil sanctions depend on the legislative solutions of the country in concern. For example, athletes convicted of doping may be sentenced to prison in the United States and Italy. The Polish CPC does not provide for this type of sanction.

In turn, any moral sanctions imposed on a player have no significance because normative ethics is discretionary and completely relative - so relative that it cannot be more relative (Kosiewicz, 2014b, pp. 5-22). What may seem reprehensible to an individual or social group (Kosiewicz, 2014b, pp. 5-22; Kosiewicz, 2014c, pp. 23-31) may be worthy of approval or even be a cause for national pride for another group. A case in point here may be the gesture of Kozakiewicz, a gold medalist of the Olympic Games in Moscow in 1980, who showed disapproval of the event's disrespectful audience. His gesture was perceived as highly negative by Russian fans, while in Poland it sparked widespread enthusiasm.

In the assessment of moral behavior and attitudes, there are countless existing and potential normative ethics, absolute and uncountable pluralism,spontaneous and rampant relativism, and the continuous radical variation of ethics - general and unfettered ethical panthareism (Kosiewicz, 2015) - even where a seemingly irrefutable moral rigor, authoritarianism, or totalitarianism has been preached.

The aggression of fans is of an amoral character both at the venue and beyond it. It is amoral in the context of aggression. It should be considered only in the context of social and individual harm. Moral context is irrelevant in this case. What is primarily important are the following:

a) skillful prevention of aggressive harmful behaviors; 
b) their appropriate neutralization in order to optimally minimize the effects of these activities;

c) deterrent, consistent, and effective penalizations for such manifestations by law (according to their seriousness), i.e., criminal law procedures (imprisonment or fines), civil law procedures (among other things, financial remedies to institutions or victims), and administrative law procedures (stadium bans).

Neither negatively aggressive sports fans (those who give trouble to society) nor ordinary sports fans are bound by regulations associated with a particular sports activity.

Aggressive fans completely disregard the moral principles and expectations of others - take hooligans or thugs for example. They are only interested in their own harmful discharge of aggression and in satisfying their own amoral needs. The author believes that only efficient preventive law enforcement activities before, during, and after sports competitions may positively influence their behavior.

\section{REFERENCES}

Aronson, E. (1995). Człowiek jako istota społeczna /The Social Animal/. Warsaw: PWN.

Aronson, E. (2007). The Social Animal. New York: Worth Publishers.

Bandura, A. (1973). Aggression: A Social Learning Analysis. New York.

Berkowitz, L. (1970). Experimental Investigations of Hostility Catharsis. Journal of Consulting and Clinical Psychology, 35, 1-7.

Bredemeier, B.J., Shields, D.L., Waiss, M.R., and Cooper, B.A.B. (1986). The Relationship of Sport Involvement with Children's Moral Reasoning and Aggression Tendencies. Journal of Sport Psychology, 8, 304-318.

Biernacka-Karolczak, B. (1998). Agresywny sport w agresywnym świecie. Percepcja sytuacji /Aggressive Sport in an Aggressive World: Perception of the Situation/. Trening, 1.

Biernacka-Karolczak, B. (2000). Agresywny sport w agresywnym świecie /Aggressive Sport in an Aggressive World: Professional Sport/. Sport Wyczynowy, 7-8.

Brown, J.M., Devies, N. (1978). Attitude Towards Violence Among College Athletes. Journal Sport of Behavior, 1, 61-70.

DeWachter, F. (1987). Education for Peace in Sport Education. In J.W. Jr. Molly, R.C. Adams (Eds.), The Spirit in Sport: Essays about Sport and Values (pp. 17-29). Bristol, Ind: Wyndham Hall Press.

Gąsowski, J. (1993). Psychologiczne problemy agresywności w sporcie /Psychological Problems of Aggression in Sport/. Sport Wyczynowy, 9-10, 13-19.

Holowchak, M.A. (2003). Aggression, Gender and Sport: Reflection on Sport as a Means of Moral Education. Journal of Social Philosophy, 34(3), 387-399.

Ingham, R. (1985). Psychologiczna i socjologiczna ocena przemocy w sporcie. Przypadek brytyjskiego chuligaństwa sportowego /Psychological and Sociological Context of Violence in Sport: The Case of British Football Hooliganism/. Kultura Fizyczna, 7-8, 29-33.

Fromm, E. (1973). The Anatomy of Human Destructiveness. New York. Polish edition: Fromm, E. (2005). Anatomia ludzkiej destruktywności. Poznań.

Kemler, D.S. (1987). Level of Athletic, Instrumental and Reactive Aggression Between Contact and Non-Contact Male High School Athletes Under Pre- and Post-Testing Conditions. Unpublished M. S. Thesis, Southern Connecticut University.

Kosiewicz, J. (2004). Filozoficzne aspekty kultury fizycznej i sportu /Philosophical Aspects of Physical Culture and Sport/. Warsaw: BK Wydawnictwo i Księgarnie.

Kosiewicz, J. (2005). Is the Fair Play Principle the Highest Value in Sport? In J. Kosiewicz (Ed.), Sport, Culture and Society (pp. 363-370). Warsaw: Wydawnictwo AWF w Warszawie.

Kosiewicz, J. (2010a). Aggression in Sport. InSport and Philosophy: From Ethics to Sport (pp. 284-295). Warsaw: BK Wydawnictwo i Księgarnie.

Kosiewicz, J. (2010b). The Sporting Spectacle from the Point of View of Aleatorism. In Sport and Philosophy: From Ethics to Sport (pp. 277-283). Warsaw: BK Wydawnictwo i Księgarnie. 
Kosiewicz, J. (2014a). Foul Play in Sport as a Phenomenon Inconsistent with the Rules, Yet Acceptable and Desirable: Ethical Conditions. Physical Culture and Sport. Studies and Research, 62, 32-47. DOI:10.2478/pcssr-2014-0010.

Kosiewicz, J. (2014b). The Normative Ethics and Sport: A Moral Manifesto, Physical Culture and Sport. Studies and Research, 62, 5-22. DOI: 10.2478/pcssr-2014-0008.

Kosiewicz, J. (2014c). Sport Beyond Moral Good and Evil. Physical Culture and Sport. Studies and Research, 62, 2331. DOI:2478/pcssr-2014-0009.

Kosiewicz, J. (2015). Why Pluralism, Relativism, and Panthareism: An Ethical Landscape with Sport in the Background. Physical Culture and Sport. Studies and Research, 66, 75-87. DOI:10.1515/pcssr-2015-0015.

Krokiewicz, A. (2000). Studia orfickie. Moralność Homera i etyka Hezjoda /Orphic Studies: The Morality of Homer and the Ethics of Hesiod/. Warsaw: Aletheia.

Li-Hong (Leo) Hsu (2005). Revisiting Fair Play: Cheating, the "Good Foul” and Sport Rules. Academic Supplement of Fair Play! The Official Publication of the European Fair Play Movement, 4, 6-7.

Lorenz, K. (1966). On Aggression. New York: Bantam Books.

Lorenz, K. (1977). Odwrotna strona zwierciadła. Próba historii naturalnej ludzkiego poznania /Behind the Mirror: A Search for a Natural History of Human Knowledge/. Warsaw: PIW.

Ossowska, M. (1966). Podstawy nauki o moralności /Foundations of the Science of Morality/. Warsaw: PWN.

Parry, J. (2002). Violence and Aggression in Contemporary Society. In M.J. McNamee., S.J. Parry (Eds.), Ethics and Sport (pp. 205-224). London and New York: Spon Press.

Reykowski, J. (1975). Zadania pozaosobiste jako regulator czynności ludzkich /Non-Personal Tasks as a Regulator of Human Activity/. In I. Kurcz, J. Reykowski (Eds.), Studia nad teorią czynności ludzkich /Studies on the Theory of Human Activity/. Warsaw.

Simon, R.L. (2007). The Ethics of Strategic Fouling: A Reply to Fraleigh. In W.J. Morgan (Ed.), Ethics in Sport (pp. 219-227). Champaign, IL: Human Kinetics.

Smith, D., Stewart, S. (2003). Sexual Aggression and Sport Participation. Journal of Sport Behavior, 26(4), $384-395$.

AUTHOR'S ADDRESS: $\quad$ Jerzy Kosiewicz

Department of Philosophy, Chair of the Social Sciences

Josef Pilsudski University of Physical Education in Warsaw

Marymoncka 34

00-968 Warsaw, Poland

Email: jerzy.kosiewicz@awf.edu.pl

Received: 14 September 2015; Accepted: 28 October 2015 